\title{
The North Atlantic Oscillation influence on Europe: climate impacts and associated physical mechanisms
}

\author{
Ricardo M. Trigo ${ }^{1,2, *}$, Timothy J. Osborn ${ }^{1}$, João M. Corte-Real ${ }^{3}$ \\ ${ }^{1}$ Climatic Research Unit, University of East Anglia, Norwich NR4 7TJ, United Kingdom \\ ${ }^{2}$ Department of Physics, and ${ }^{3}$ Institute for Applied Science and Technology (ICAT), Faculty of Sciences, University of Lisbon, \\ 1749-016 Lisbon, Portugal
}

\begin{abstract}
A multivariable analysis of the influence of the North Atlantic Oscillation (NAO) on the climate of the North Atlantic and European sectors is presented using the $40 \mathrm{yr}$ (1958-1997) consistent data set from NCEP. Using high and low NAO index composites, anomaly fields of climate variables are then interpreted based on physical mechanisms associated with the anomalous mean flow (characterised by the surface wind field) and the anomalous eddy activity (characterised by the surface vorticity and the $500 \mathrm{hPa}$ storm track fields). It is shown that NAO-related temperature patterns are mainly controlled by the advection of heat by the anomalous mean flow. However, large asymmetries between minimum and maximum temperatures, and more significantly, between positive and negative phases of NAO imply the importance of a different mechanism, namely, the modulation of short wave and long wave radiation by cloud cover variations associated with the NAO. Furthermore, NAO influence on 2 different precipitation-related variables - precipitation rate and precipitable water-displays different patterns. Precipitable water is shown to be strongly related to the corresponding anomaly fields of temperature while precipitation rate appears to be controlled by the surface vorticity field and associated strength of the tropospheric synoptic activity.
\end{abstract}

KEY WORDS: NAO - Storm tracks - Surface wind - Maximum and minimum temperatures . Precipitation rate $\cdot$ Precipitable water

Resale or republication not permitted without written consent of the publisher

\section{INTRODUCTION}

The North Atlantic Oscillation (NAO) has been recognised for more than $60 \mathrm{yr}$ as one of the major patterns of atmospheric variability in the Northern Hemisphere (Walker 1924, Walker \& Bliss 1932). This important circulation mode has been characterised more comprehensively over the last 2 decades (e.g., Rogers 1984, Barnston \& Livezey 1987, Hurrell 1995, Hurrell \& van Loon 1997). In simple terms, the NAO corresponds to a large-scale meridional oscillation of atmospheric mass between the subtropical anticyclone near the Azores and the subpolar low pressure system

*E-mail: rtrigo@fc.ul.pt near Iceland (van Loon \& Rogers 1978). Recently, a number of different studies have shown the relevance of the NAO to the winter surface climate of the Northern Hemisphere in general and over the Atlantic/ European sector in particular (Hurrell 1995, 1996, Rogers 1997, Qian et al. 2000). Additional studies have established links between different NAO modes and changes in the associated activity of North-Atlantic storm tracks (Serreze et al. 1997, Osborn et al. 1999, Ulbrich et al. 1999). The existence of 2 contemporaneous and possibly related winter-time trends over the last 3 decades: a trend towards the positive phase of the NAO and a trend towards warmer Northern Eurasian land temperatures has now been established (Wallace et al. 1995, Hurrell 1996, Hurrell \& van Loon 1997). These results have prompted an increas- 
ing number of modelling studies to reproduce the NAO pattern (Saravanan 1998), as well as much of its influence on the climate and storm track paths over the Northern Atlantic region (Osborn et al. 1999, Ulbrich \& Christoph 1999). The role played by North Atlantic sea surface temperature anomalies in modifying the NAO pattern has also been demonstrated recently through the use of an ensemble of runs with an atmospheric general circulation model (Rodwell et al. 1999, Mehta et al. 2000).

Despite the increasingly widespread use of NAO as a key circulation mode in determining the climate over the northern Atlantic region, most applications tend to restrict the study to the observed mean monthly temperature and precipitation. In particular, there has been no comprehensive simultaneous analysis of the maximum and minimum temperatures, winds, storm tracks and different precipitation-related variables. Furthermore, an equally restricted number of studies make explicit use of dynamical variables that can provide a physical explanation to the spatial distribution of NAO-related climatic anomalies.

The main objective of this paper is to present a multivariable description of the NAO impacts on the climate of the Atlantic and the European sectors using a comprehensive suite of variables. Data and the composite methodology are briefly introduced in Section 2 . Then, Sections 3 to 5 illustrate the analysis of the composites for different variables for the positive and negative phases of the NAO, namely, maximum and minimum temperatures (hereafter Tmax and Tmin), precipitable water and precipitation rate. The interpretation of the physical mechanisms that generate the anomaly fields of these variables will be attempted by means of corresponding anomaly fields of surface wind and vorticity fields and $500 \mathrm{hPa}$ storm track. Finally a discussion and some conclusions are presented in Section 6.

\section{DATA AND METHOD}

Historically, the NAO has been defined as a simple index that measures the difference in surface pressure between Ponta Delgada in the Azores and the Icelandic station of Stykkisholmur. According to some authors, a better determination of the dipole's centres of action can be attained by the application of principal component analysis (PCA) to sea level pressure (SLP) or tropospheric geopotential height (Wallace \& Gutzler 1981, Barnston \& Livezey 1987). Wallace (2000) states that, unlike PCs, the simple station-based indices are not optimal representations of the temporal behaviour of their own associated spatial patterns. Despite these advantages associated with a PC analysis, the use of PCA to define the NAO index can be undermined by the fact that empirical orthogonal function (EOF) patterns and corresponding $\mathrm{PC}$ time series are dependent on the size of the window used. For example, the first EOF obtained with the application of a PCA to the SLP of the entire Northern Hemisphere corresponds to the hemispheric mode of the AO (Arctic Oscillation) and not to the more regionalised NAO pattern (Thompson \& Wallace 1998). In a previous work, the authors have shown that NAO indices derived from a PCA approach or from the 'standard' SLP difference are very similar (Osborn et al. 1999). Accordingly we decided to use the GibraltarIceland normalised index (Fig. 1) developed and maintained at the Climatic Research Unit (Jones et al. 1997). The advantages of using Gibraltar (instead of Ponta Delgada) and also of a longer winter season (DJFM) have been comprehensively discussed in previous works (Jones et al. 1997, Osborn et al. 1999).

Except for cloud cover, all data used in this study are large-scale gridded data retrieved from the National Centers for Environmental Prediction (NCEP) Reanalysis data sets for the period 1958-1997. The Reanalysis data were derived through a consistent assimilation and forecast model procedure that incorporated all available weather and satellite information (Kalnay et al. 1996). Six-hourly values of SLP, $500 \mathrm{hPa}$ geopotential height, precipitable water, precipitation rate, $2 \mathrm{~m}$ height maximum and minimum temperatures and $10 \mathrm{~m} u$ and $v$ wind components were extracted for the NCEP $2.5^{\circ}$ latitude by $2.5^{\circ}$ longitude grid, for the area $30-80^{\circ} \mathrm{N}, 60^{\circ} \mathrm{W}-70^{\circ} \mathrm{E}$. Daily values were computed by averaging those 6 -hourly values, with the exception of Tmax and Tmin, for which 1 daily value was used. It must be remembered that, though based on observational data, the Reanalysis data are also dependent

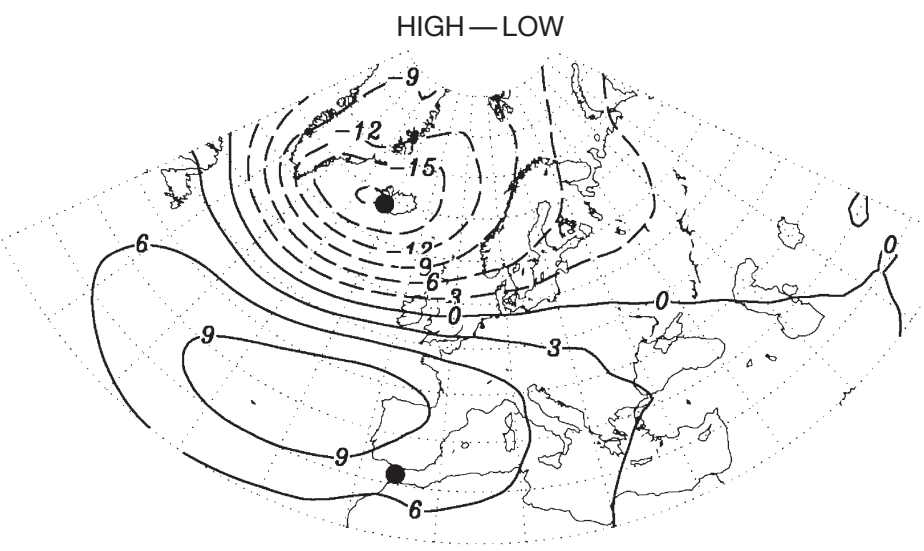

Fig. 1. Difference in SLP (hPa) between winter months (DJFM) with an NAO index >1.0 and with an NAO index <-1.0 from 1958 to 1997. $(\bullet)$ Locations of station observations from Gibraltar and Iceland 
upon the skill and reliability of the forecast model. Kalnay et al. (1996) categorise the reliance on the model of different types of variables; precipitation rate is a member of the class of variables that are most dependent upon the forecast model, and model systematic errors may introduce erroneous precipitation data. Nevertheless, Reanalysis precipitation has been shown to present some skill in comparison with observations (e.g., Stendel \& Arpe 1997, Trenberth \& Guillemot 1998, Widmann \& Bretherton 2000). Stendel \& Arpe (1997) performed a comprehensive comparison of the hydrological cycle for different Reanalysis projects, namely NCEP, ECMWF (European Centre for Medium-Range Weather Forecasts), NASA (National Aeronautics and Space Administration) and observed data sets (including satellite data). These authors show that the NCEP scheme presents a dry (wet) bias during the winter (summer) season over Central Europe, thus affecting the region under study. Furthermore, Stendel \& Arpe prove that, overall, precipitation fields derived with the ECMWF Reanalysis possess superior quality to NCEP Reanalysis over the extratropical region. However, it is necessary to bear in mind that all the analyses performed in this paper are based on the use of anomaly composites (mean field removed), which considerably removes the impact of model inadequacies on our results.

Monthly values of cloud cover between 1958 and 1995 were obtained from the high resolution $\left(0.5^{\circ}\right.$ latitude by $0.5^{\circ}$ longitude) data set developed recently by the Climatic Research Unit (New et al. 1999, 2000). This data set uses a dense network of observations, particularly over Europe and for the period that spans the early 1960s to the early 1990s (New et al. 2000).

Composites of all analysed NCEP fields between December and March from 1958 to 1997 were derived following the procedure developed by Hurrell (1995). However, unlike the Hurrell procedure, composites of high (low) NAO index were produced using a monthly (not seasonal) criterion. Thus composites were obtained on a monthly basis containing only those months where the NAO index is $>1$ (high NAO composite) or $<-1$ (low NAO composite). The number of months with a high NAO index is slightly higher (64) than those characterized by a low NAO index (43). The remaining months (53) are characterized by 'near-normal' values of the NAO index. The spatial signature of the NAO is represented by the difference in SLP between composites of winter months (DJFM) with an NAO index $>1.0$ and with an NAO index < -1.0 from 1958 to 1997 (Fig. 1). This shows the expected dipole between the Iceland and the Azores regions. The southern centre of action is not centred over the Gibraltar station used in the NAO index, because the variance of SLP is lower there than over the Azores, and thus the magnitude of the composite anomaly is greater over the Azores.

\section{STORM TRACKS}

In recent years, 2 distinct approaches have been used to study the storm activity over the North Atlantic and Europe:

(1) Storm track algorithms. These are usually sophisticated methods that can detect the regions of storm development (cyclogenesis) and decay (cyclolysis) as well as the specific paths of each individual storm (Murray \& Simmonds 1991, Serreze et al. 1997, Trigo et al. 1999). In particular, Serreze et al. (1997) have shown the areas of significant difference in storm activity between winters with high and low NAO indices.

(2) Synoptic variability. This simpler approach corresponds to the identification of the synoptic variability using a band-pass filter that retains mainly variability on the 2 to $8 \mathrm{~d}$ period range. Recently, this approach has also been applied to SLP fields to quantify the synoptic activity associated with high and low NAO indices (Hurrell \& van Loon 1997, Rogers 1997, Ulbrich \& Christoph 1999). Here, we adopted this second approach.

Following the procedure developed in a previous work (Osborn et al. 1999), daily gridded $500 \mathrm{hPa}$ geopotential height data, spanning the period 1 December to 31 March from 1958 to 1997, were filtered in a way that maximizes the response for the 2 to $8 \mathrm{~d}$ periodicity range (Rogers 1997). The root mean square of the band-pass-filtered data provides a proxy for $500 \mathrm{hPa}$ synoptic variability at each grid point and for each winter month. However, it should be emphasised that this measure of synoptic variability can be driven by more than just storm centres. Here, the term 'storm track' will be used interchangeably with the terms 'synoptic activity' or 'transient eddy activity', with the implicit understanding that these storm tracks correspond to preferred paths of both negative and positive synoptic-scale perturbations (Lau 1988).

The observed climatological field of storm track activity (not shown) presents a maximum between Newfoundland and the Icelandic low region. This is in agreement with previous works that have used the SLP band-pass filtered field (Fig. 1 of Rogers 1997). Furthermore, it is also in conformity with objective storm track procedures (as seen, e.g., in Fig. 1b of Serreze et al. 1997).

The absolute values of synoptic activity for months of high and low NAO index are shown in Fig. 2. Composites of the high NAO index show an extended strong maximum of transient eddy activity 
a

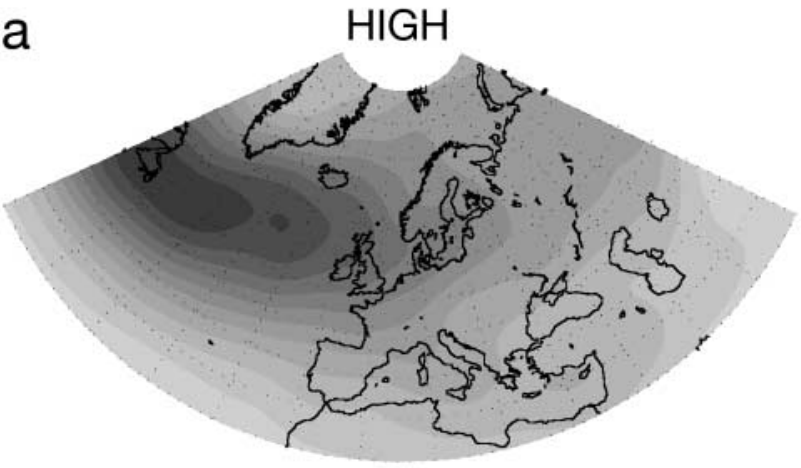

b

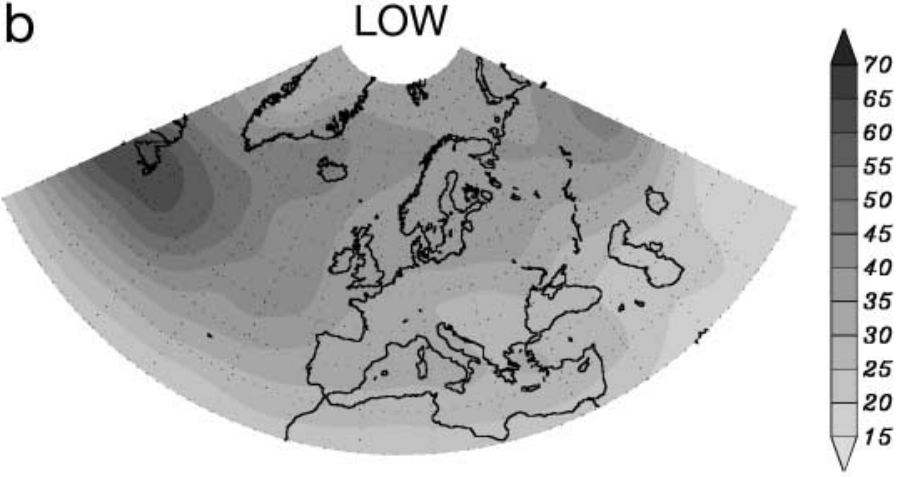

C

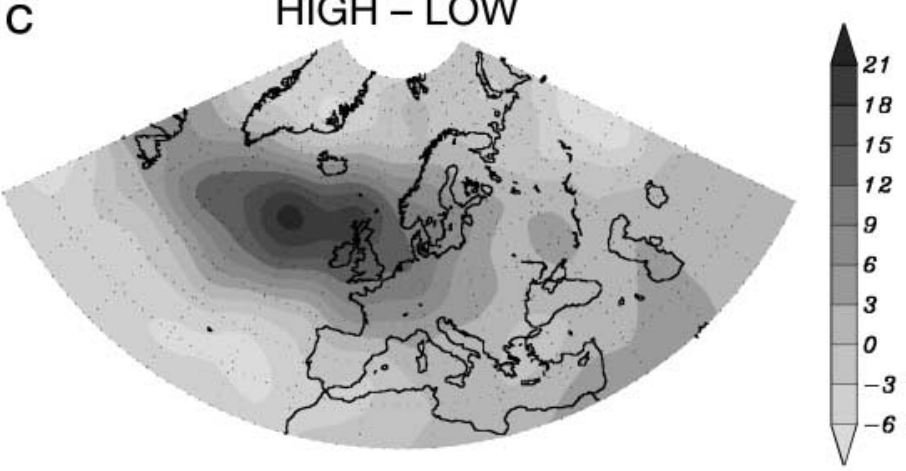

Fig. 2. Composites of synoptic activity (gpm) for the winter months (DJFM) of the 1958 to 1997 period: (a) NAO index $>1.0$, (b) NAO index $<-1.0$, and (c) their difference

spanning between Newfoundland and the British Isles (Fig. 2a). In contrast, months characterized by a low NAO index present a much more localized maximum over Newfoundland with weak extensions into the Scandinavian and Iberian peninsulas (Fig. 2b). As expected, the difference in synoptic activity between these high and low NAO index composites presents a concentration of the highest positive values west of the British Isles and a spread of weaker negative values over southern and northern latitude bands (Fig. 2c).

\section{MAXIMUM AND MINIMUM TEMPERATURES}

No systematic evaluation of NCEP maximum and minimum temperatures has been undertaken. However, Chelliah \& Ropelewski (2000) present a comprehensive comparison of surface mean temperatures for different Reanalysis projects (ECMWF, NCEP, NASA) and observed data sets (including satellite data). Their results show that the NCEP Reanalysis scheme is able to reproduce the spatial pattern of surface temperature anomalies of Jones (1991) as well as its evolution in time (see their Figs 12-14). It has to be emphasised that surface temperature observations are not assimilated in the NCEP assimilation system, but are instead a modelderived quantity in the NCEP reanalysis (Kalnay et al. 1996). Again, the use of anomaly composites eliminates the impact on our results of model inadequacies that relate only to a poor simulation of the mean temperature field.

The impact of the NAO on the mean temperature of the region has been described in previous works (e.g., Hurrell 1996, Osborn et al. 1999). However, to the best of our knowledge, a separate analysis developed independently for the Tmax and Tmin fields has not been attempted. Here, such an analysis is presented. Anomaly fields of Tmax (Tmin) for months of high and low NAO index can be observed in Fig. 3a,b (Fig. 4a,b). These anomaly fields were computed after removing the winter climatology from the corresponding composited monthly fields of high and low NAO index composites.

During positive phases of NAO, the Atlantic meridional SLP gradient is enhanced, contributing to the strengthening of the westerly wind field (Figs 3a \& 4a). Such strengthening of the westerlies is responsible for an increased advection of moist warm air to the northeast, producing warmer conditions over Scandinavia and part of northern Russia. An interesting new result is that this anomalous warmth also extends to much of Central Europe (and even into the Iberian Peninsula, northern Italy and the Balkans) for daytime maximum temperature (Fig. 3a), but not for the night-time minimum temperature (Fig. 4a). It will be shown later (Section 5) that for positive NAO winter months, Central Europe and the Iberian Peninsula experience anomalously anticyclonic circulation and reduced precipitation (see Fig. 6a), and these are associated with reduced cloud cover (see Fig. 5a). The additional daytime incoming solar radiation and night-time outgoing long-wave radiation is able to explain the difference between Tmax and Tmin composites. On the western side of the North Atlantic basin, a large area of strong negative anom- 

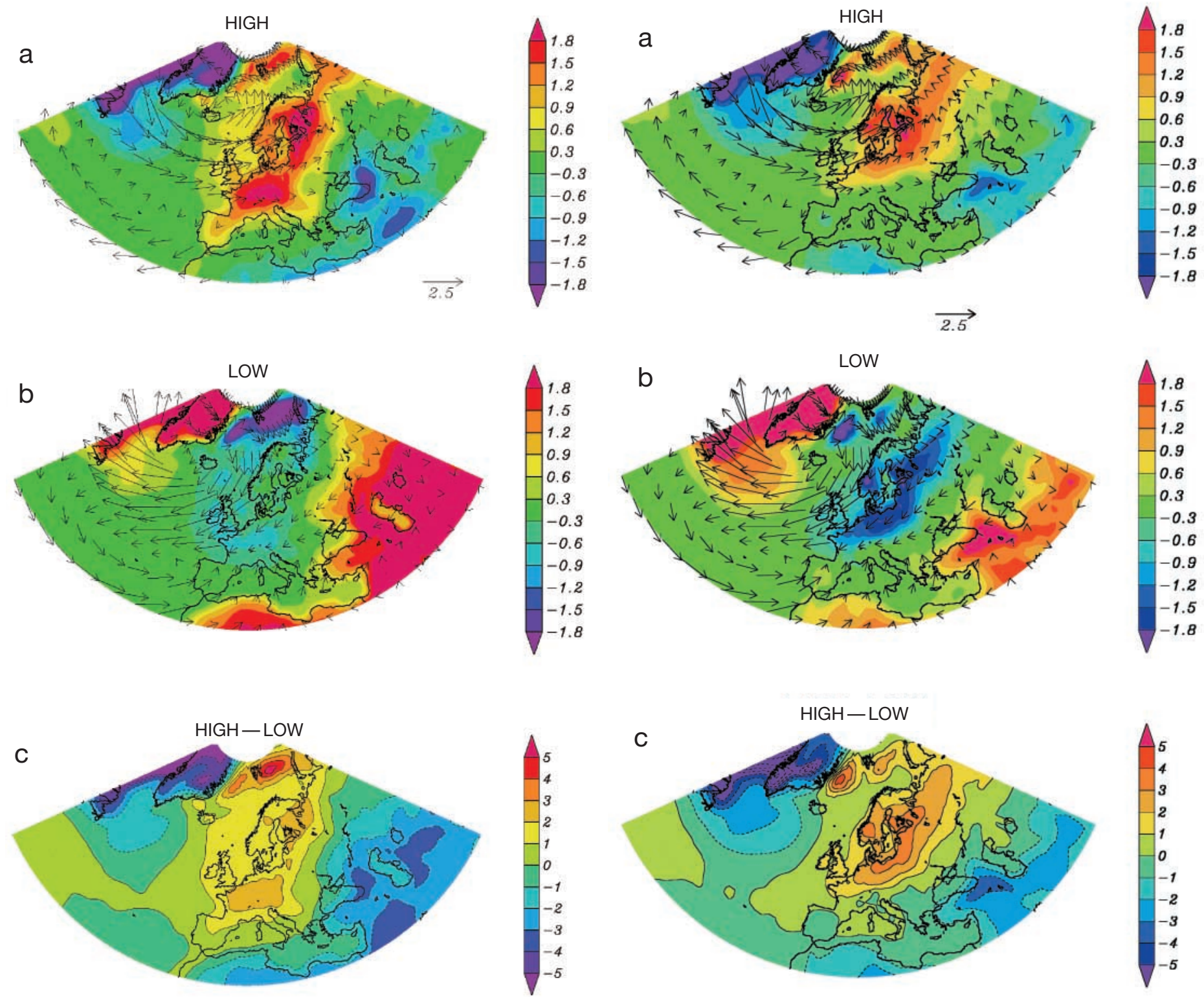

Fig. 3. Tmax anomaly fields $\left({ }^{\circ} \mathrm{C}\right)$ for winter months with (a) high NAO index $>1.0$, (b) low NAO index $<-1.0$, and (c) their difference. Vectors of the anomaly $10 \mathrm{~m}$ wind field $\left(\mathrm{m} \mathrm{s}^{-1}\right)$ for months with (a) high and (b) low NAO indices are also represented

alies develops between Newfoundland and Greenland as a result of the strong advection of cold air from polar latitudes and from the cold continent.

During negative phases of NAO, the meridional SLP gradient is weakened, favoring the advection of warm Atlantic air over a Newfoundland and Greenland sector that is responsible for a large area of positive anomalies of both Tmax (Fig. 3b) and Tmin (Fig. 4b). Furthermore, a strong meridional flow anomaly from the Arctic region effectively advects cold air into Northern Europe.

Fig. 4. Tmin anomaly fields. Legend as for Fig. 3

However, the impact of such cold continental flow over Northern Europe is significantly larger for Tmin than for Tmax (Figs 3b \& 4b). The asymmetric response of the Tmax and Tmin fields over Europe are mainly caused by the lack of clouds during typical synoptic situations that characterise the negative phase of NAO over Northern Europe (Fig. 5b), namely blocking anticyclones and easterly flow (see, e.g., Wilby et al. 1997). It is worth noting that Tmax values are usually recorded during daylight, while Tmin values are usually observed towards the end of the night. Thus, during daytime enhanced solar short-wave radiation is capable of partially offsetting the advection of cold polar air to yield small Tmax anomalies, while during the night the 
strong clear sky emission of long-wave radiation further cools the lower troposphere.

The large-scale mean temperature anomalies can be mostly explained by heat transport by the corresponding anomalous mean atmospheric flow (see the $10 \mathrm{~m}$ wind velocity anomalies superposed on Figs 3 \& 4), modified and partially offset by the heat transported by transient eddies (see Fig. 12 of Hurrell \& van Loon 1997 and Fig. 8 of DeWeaver \& Nigam 2000). However, the analysis presented here demonstrates the importance of a third process. This process is the modulation by anomalous cloud cover (associated with anomalous atmospheric circulation) of the radiative transfer of heat to and from the earth's surface. These radiative and cloud cover influences modulate the response to NAO mainly in terms of generating different day and night-time temperature anomalies.

The difference in Tmax (Tmin) between months of high and low NAO index are shown in Fig. 3c (Fig. 4c). As expected, the largest differences can be found over northern Europe, Newfoundland/Greenland and over the northern Africa/Caspian Sea region. The amplitude of the differences over Europe is larger for Tmin than for Tmax. However, the spatial extension of such differences for the northern Africa/Caspian Sea area is larger for Tmax than for Tmin. Interestingly, both Tmax and Tmin present important high-latitudinal anomalies over the Greenland Sea and to the east of Spitsbergen. It is possible that the anomalous mean circulation previously described could be driving a corresponding anomalous distribution of sea-ice over those 2 regions, thus contributing to the negative (positive) Tmax and Tmin anomalies for low (high) NAO index composites (see Dickson et al. 2000, for further discussion of the high latitude response to the NAO).

\section{PRECIPITATION}

In Section 3 we showed that changes of the mean circulation are accompanied by important shifts of the associated storm tracks. Previous studies have established that such changes can be directly linked with significant changes of regional precipitation over most of Europe, northern Africa and, to a certain extent, North America (Hurrell 1995, Hurrell \& van Loon 1997, Osborn et al. 1999). Recently, the precipitation impact of NAO over Europe has been quantified using 2 different approaches: first, the use of raingauge-based, land-only precipitation observations
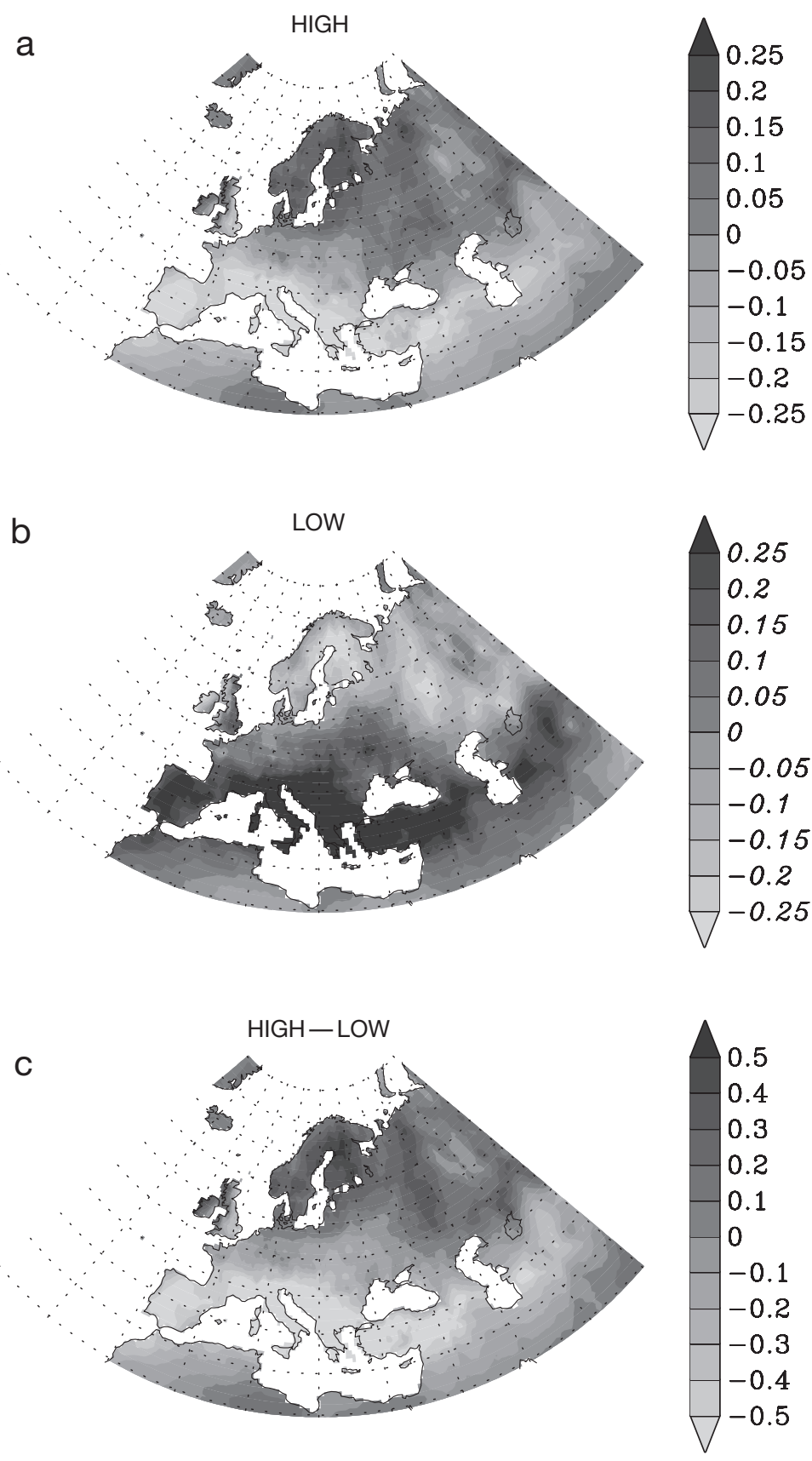

Fig. 5. Cloud cover anomaly fields (oktas) for winter months. (a) NAO index $>1.0$, (b) NAO index $<-1.0$ and (c) their difference

(e.g., Fig. 14 in Hurrell \& van Loon 1997); and second, plots of evaporation minus precipitation $(E-P)$, computed as a residual of the atmospheric moisture budget from analysis data sets (e.g., Hurrell 1995 and Fig. 13 in Hurrell \& van Loon 1997). Despite being closer to 'reality', the first approach is undermined by a lack of data over many areas, especially over the oceans. In contrast, the second approach can be applied to both land and oceans; however, the short length of the 
analysis period ( $15 \mathrm{yr}$ ) could undermine the stability of the NAO-related patterns obtained in Hurrell (1995) and Hurrell \& van Loon (1997). Thus it is understandable that results obtained with these 2 methods are not in complete agreement (compare, e.g., Figs 13 \& 14 in Hurrell \& van Loon 1997). NCEP Reanalysis data sets can partially diminish this problem by providing a 40-yr-long, global coverage of consistent precipitationrelated data. Here, monthly means of 2 reanalysed variables, namely, daily precipitation rate and precipitable water are used (hereafter PR and PW, respectively). It is necessary to bear in mind that PR variables obtained using the NECP assimilation/forecast model procedure are susceptible to model-systematic errors and should not be considered as totally reliable (Kalnay et al. 1996).

PR anomaly fields for winter months characterised by high and low NAO index values are shown in Fig. 6a,b, respectively. Both panels present quasi-zonal bands of opposite anomaly signs. This fact is clearly depicted by the high-low NAO index field represented in Fig. 6c. Positive anomaly values of PR are concentrated in the northern latitudes and extend from southern Greenland to northern Russia, with maxima near Iceland and Scotland. At lower latitudes, a strong negative band of PR spans from the eastern USA coast across the Atlantic into Iberia, presenting a weaker elongation across the Mediterranean until the Middle East. Finally, a smaller but consistently positive anomaly can be detected over eastern parts of North Africa and the south-eastern Mediterranean. Such positive and negative patterns over the continent and the Mediterranean Basin are in good agreement with previous results (compare Fig. 6c with the European-only Fig. 14 of Hurrell \& van Loon 1997, or Fig. 7a of Osborn et al. 1999).

Enhanced precipitation should be explainable in terms of enhanced moisture availability and/or conditions that enhance condensation of water vapour. PW provides a measure of the first term, being the total water vapour content in a vertical column of the atmosphere. PW anomaly fields for winter months characterised by high and low NAO index values are shown in Fig. $7 a, b$, respectively. Unlike the PR case, the impact of NAO is characterised by non-zonal bands of positive and negative regions of PW. In fact, Fig. 7a (Fig. 7b) shows that months with a high (low) NAO index value present a positive (negative) anomaly band extending (with a southwestern-northeastern orientation) from southern Newfoundland across the British Isles and into northern Russia. This diagonal band is bordered by 2 regions of opposite anomaly signals, one presenting strong concentrated maxima values south of Greenland and the other presenting broader band of not so intensive anomaly values from the subtropical Atlantic, across the Mediterranean and into the Middle East. The characteristics of these 3 regions, which display large symmetries in both months with high and low NAO index, are enhanced in the high-low field (Fig. 7c). It is well known that the water vapour content in a column of atmosphere is highly associated with the temperature of that same column. So, the large-scale features of the high-low PW field (Fig. 7c) are different from the equivalent PR features (Fig. 6c) but consistently more similar to the corresponding atmospheric temperature anomaly patterns (i.e., the average of the Tmax [Fig. 3c] and Tmin [Fig. 4c] patterns).

Condensation of the precipitable water content typically requires uplift provided by a range of mechanisms, but principally low-level convergence associated with cyclonic circulation (i.e., positive vorticity). In fact, the vorticity field (computed from the $10 \mathrm{~m}$ wind field monthly composites) indicates that much of the PR response to high (Fig. 6a) and low (Fig. 6b) NAO index values is associated with anomalous values of the vorticity field. The maximum value of positive (negative) vorticity, represented by solid (dashed) lines, is consistently located a few degrees north of regions with higher (lower) than average PR values. This northward shift of the vorticity maxima is compatible with the typical configuration of a mid-latitude synoptic disturbance, with the low-pressure centre positioned poleward of the fronts that induce precipitation through strong vertical motions. In summary, PR anomalies (Fig. 6) can be mainly attributed to the vorticity of the mean composite circulation (Fig. 6), but as well to the NAOrelated transient circulation features (Fig. 2) and PW patterns (Fig. 7).

\section{DISCUSSION AND CONCLUSIONS}

The influence of NAO on temperature and precipitation over Europe and the North Atlantic has previously been well documented. Here we take further steps by analysing additional climate variables (using the NCEP Reanalysis data set) and by attempting a physical explanation of linkage between variables.

The pattern of daily mean temperature associated with the NAO can be well explained by the advection of heat by the anomalous mean flow which, once initiated, is balanced and slightly modified by the heat transport by transient eddies (Hurrell \& van Loon 1997). Here, we invoke an additional mechanismnamely the modulation of short-wave and long-wave radiation by cloud-cover variations associated with the NAO-to explain the patterns of daily maximum and minimum temperatures. The NAO-related Tmin 

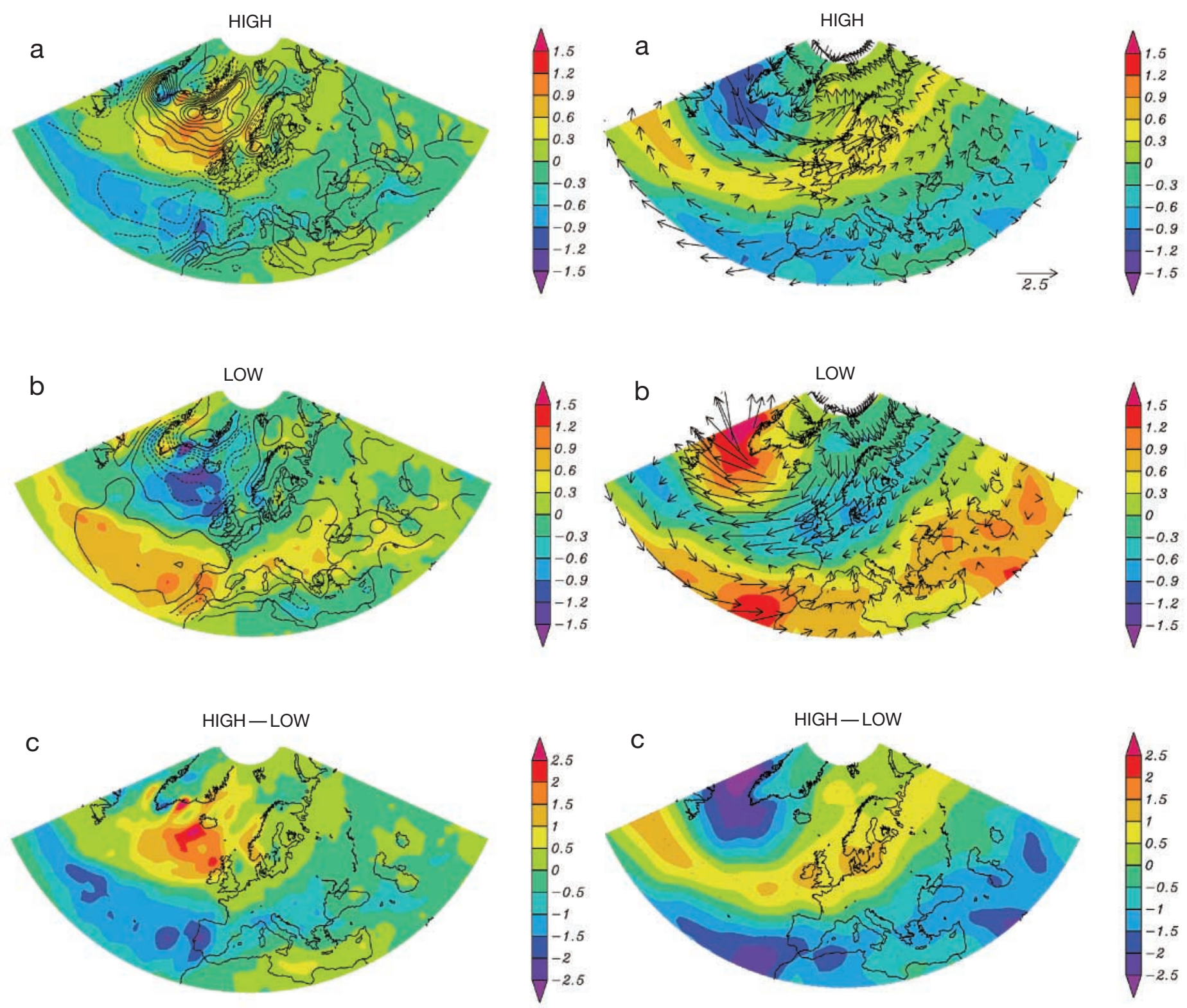

Fig. 6. Precipitation rate anomaly fields $\left(\mathrm{mm} \mathrm{d}^{-1}\right)$ for winter months with (a) high NAO index $>1.0$, (b) low NAO index $<-1.0$, and (c) their difference. Positive (solid) and negative (dashed) isolines of the $10 \mathrm{~m}$ anomaly vorticity field, for months with (a) high and (b) low NAO indices are also represented

and Tmax patterns show asymmetries, both between Tmin and Tmax and between positive and negative phases of NAO. Overall, the NAO signal is stronger in Tmin than in Tmax. This result, in itself, is of considerable interest: if recent trends towards a positive phase of the winter NAO can be used to explain recent winter warming of the Northern Hemisphere land surface (Hurrell 1996), then our results imply that it might also be able to explain the stronger recent warming trend in the minimum (night-time)

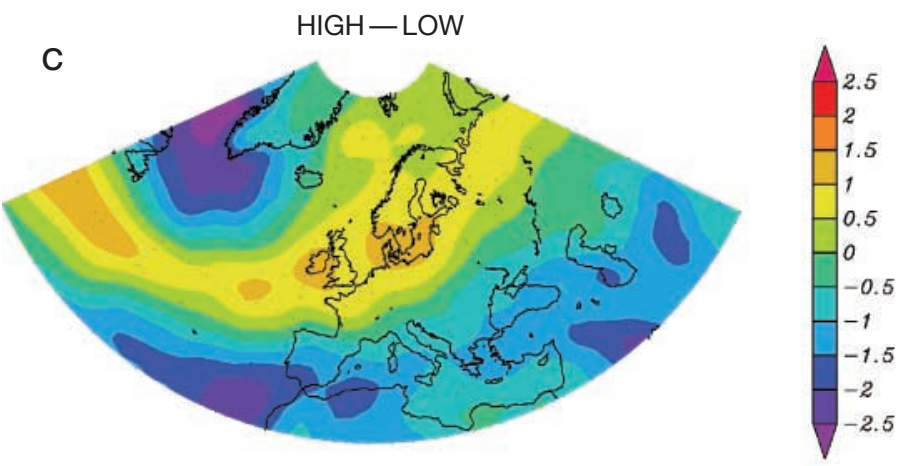

Fig. 7. Precipitable water anomaly fields $\left(\mathrm{mm} \mathrm{d}^{-1}\right)$. Legend as for Fig. 3

temperature relative to the maximum (daytime) temperature (Karl et al. 1993).

For precipitation-related variables, we find quite distinct patterns of precipitable water content and precipitation rate associated with NAO. The former is quite strongly controlled by the corresponding anomaly fields of temperature. Precipitation rate (as estimated by the NCEP Reanalysis system), on the other hand, appears to be related to the precipitable water content and atmospheric circulation patterns conducive to the condensation of the available moisture (measured here by the vorticity of the composite $10 \mathrm{~m}$ wind field and by the strength of the $500 \mathrm{hPa}$ synoptic eddy activity). 
Acknowledgements. R.M.T. was supported with a grant (BD/5734/95-RN) from FCT (Portugal) under the PRAXIS program. Financial assistance has also been provided by the Gulbenkian Foundation and by the UK NERC (GR3/12107). The authors would like to thank Isabel Trigo for providing the storm track algorithm and Ian Harris and David Viner of the Climatic Research Unit for providing the NCEP Reanalysis data.

\section{LITERATURE CITED}

Barnston AG, Livezey RE (1987) Classification, seasonality and persistence of low-frequency atmospheric circulation patterns. Mon Weather Rev 115:1083-1127

Chelliah M, Ropelewski CF (2000) Re-analyses-based tropospheric temperature estimates: uncertainties in the context of global climate change detection. J Clim 13: 3187-3205

DeWeaver E, Nigam S (2000) Zonal-eddy dynamics of the North Atlantic Oscillation. J Clim 13:3893-3914

Dickson RR, Osborn TJ, Hurrell JW, Meincke J, Blindheim J, Adlandsvik B, Vigne T, Alekseev G, Maslowski W (2000) The Arctic Ocean response to the North Atlantic Oscillation. J Clim 13:2671-2696

Hurrell JW (1995) Decadal trends in the north Atlantic oscillation: regional temperatures and precipitation. Science 269:676-679

Hurrell JW (1996) Influence of variations in extratropical wintertime teleconnections on Northern Hemisphere temperature. Geophys Res Lett 23:665-668

Hurrell JW, van Loon H (1997) Decadal variations in climate associated with the North Atlantic Oscillation. Clim Change 36:301-326

Jones PD, Wigley TML, Farmer G (1991) Marine and land temperature data sets: a comparison and look at recent trends. In: Schlesinger ME (eds) Greenhouse-gas-induced climatic change: a critical appraisal of simulation and observations. Elsevier Science, Amsterdam, p 593-602

Jones PD, Jonsson T, Wheeler D (1997) Extension to the North Atlantic Oscillation using instrumental pressure observations from Gibraltar and south-west Iceland. Int J Climatol $17: 1433-1450$

Kalnay E, Kanamitsu M, Kistler R, Colins W and 18 others (1996) The NCEP/NCAR 40-years reanalyses project. Bull Am Meteorol Soc 77:437-471

Karl TR, Jones PD, Knight RW, Kukla G and 6 others (1993) Asymmetric trends of daily maximum and minimum temperature. Bull Am Meteorol Soc 74:1007-1023

Lau NC (1988) Variability of the observed midlatitude storm tracks in relation to low-frequency changes in the circulation pattern. J Atmos Sci 45:2718-2743

Mehta VM, Suarez MJ, Manganello JV (2000) Oceanic influence on the North Atlantic Oscillation and associated northern hemisphere climate variations: 1959-1993. Geophys Res Lett 27:121-124

Murray RJ, Simmonds I (1991) A numerical scheme for tracking cyclones centres from digital data. Part I: Development and operation of the scheme. Aust Meteorol Mag 39: 155-166

New MG, Hulme M, Jones PD (1999) Representing twentiethcentury space-time climate variability. Part I: Development of a 1961-90 mean monthly terrestrial climatology. J Clim 12:829-856

New MG, Hulme M, Jones PD (2000) Representing twentiethcentury space-time climate variability. Part II: Develop-

Editorial responsibility: Hans von Storch,

Geesthacht, Germany ment of a 1901-95 monthly grids of terrestrial surface climate. J Clim 13:2217-2238

Osborn TJ, Briffa KR, Tett SFB, Jones PD, Trigo RM (1999) Evaluation of the North Atlantic Oscillation as simulated by a climate model. Clim Dyn 15:685-702

Qian B, Corte-Real J, Xu H (2000) Is the North Atlantic Oscillation the most important atmospheric pattern for precipitation in Europe? J Geophys Res 105:11901-11910

Rodwell MJ, Rowell DP, Folland CK (1999) Oceanic forcing of the wintertime North Atlantic Oscillation and European climate. Nature 398:320-323

Rogers JC (1984) The association between the North Atlantic Oscillation and the Southern Oscillation in the Northern Hemisphere. Mon Weather Rev 112:1999-2015

Rogers JC (1997) North Atlantic storm track variability and its association to the North Atlantic Oscillation and climate variability of northern Europe. J Clim 10:1635-1647

Saravanan R (1998) Atmospheric low-frequency variability and its relationship to midlatitude SST variability: studies using NCAR climate system model. J Clim 11:1386-1404

Serreze MC, Carse F, Barry RG, Rogers JC (1997) Icelandic Low cyclone activity: climatological features, linkages with the NAO, and relationships with recent changes in the Northern Hemisphere circulation. J Clim 10:453-464

Stendel M, Arpe K (1997) Evaluation of the hydrological cycle in re-analysis and observations. ECMWF Re-Analysis Validation Reports-Part 1. ECMWF RE-Analysis Project Report Series 6, ECMWF, Reading

Thompson DWJ, Wallace JM (1998) The Arctic Oscillation signature in the wintertime geopotential height and temperature fields. Geophys Res Lett 25:1297-1300

Trenberth KE, Guillemot CJ (1998) Evaluation of the atmospheric moisture and hydrological cycle in the NCEP/ NCAR reanalyses. Clim Dyn 14:213-231

Trigo IF, Davies TD, Bigg GR (1999) Objective climatology of cyclones in the Mediterranean region. J Clim 12:1685-1696

Ulbrich U, Christoph M (1999) A shift in the NAO and increasing storm track activity over Europe due to anthropogenic greenhouse gas. Clim Dyn 15:551-559

Ulbrich U, Christoph M, Pinto JG, Corte-Real J (1999) Dependence of winter precipitation over Portugal on NAO and baroclinic wave activity. Int J Climatol 19:379-390

van Loon H, Rogers JC (1978) The seesaw in winter temperatures between Greenland and Northern Europe, Part 1: general description. Mon Weather Rev 106:296-310

Walker GT (1924) Correlations in seasonal variations of weather. IX Mem Ind Meteorol Dept 24:275-332

Walker GT, Bliss EW (1932) World weather, V. Mem R Meteorol Soc 4:53-84

Wallace JM (2000) North Atlantic Oscillation/annular mode: two paradigms - one phenomenon. Q J R Meteorol Soc 126:791-805

Wallace JM, Gutzler DS (1981) Teleconnections in the geopotential height field during the Northern Hemisphere winter. Mon Weather Rev 109:784-812

Wallace JM, Zhang Y, Renwick JA (1995) Dynamic contributions to the hemispheric mean temperature trends. Science 270:780-783

Widmann M, Bretherton CS (2000) Validation of mesoscale precipitation in the NCEP reanalysis using a new gridcell data set for the northwestern United States. J Clim 13: 1936-1950

Wilby RL, O'Hare G, Barnsley N (1997) The North Atlantic Oscillation and the British Isles climate variability 1865-1995. Weather 52:266-276

Submitted: October 12, 2000; Accepted: June 24, 2001

Proofs received from author(s): November 26, 2001 